RU Метафорическая репрезентация медиаобраза вооруженных сил (на примере ВС РФ и НОАК)

\author{
Калинин О. И., Радус Л. А.
}

Аннотация. Цель исследования - выявить специфику метафорического содержания образа вооруженных сил России и КНР. В статье проясняется роль метафор в формировании институционального образа в медиадискурсе, обосновывается возможность исследования метафор для выявления специфики концептуального осмысления общественно-политических концептов. Научная новизна исследования состоит в выделении имиджеобразующей функции метафоры и проведении практического анализа метафорической репрезентации медиаобраза армий России и Китая. Полученные результаты показали, что основой образа китайских вооруженных сил является «единство с народом» и «способность к защите страны», а образ ВС РФ не имеет системной метафорической манифестации, используемые метафоры Армии России носят эпизодический характер.

\title{
EN Metaphorical Representation of the Media Image of the Armed Forces (by the Example of the Armed Forces of the Russian Federation and the Chinese People's Liberation Army)
}

\author{
Kalinin O. I., Radus L. A.
}

\begin{abstract}
The purpose of the research is to identify the specificity of the metaphorical content of the image of Russian and Chinese armed forces. The paper clarifies the role that metaphors play in the formation of an institutional image in media discourse, substantiates the possibility of studying metaphors to identify the specificity of the conceptual understanding of socio-political concepts. Scientific novelty of the research lies in accentuating the image-building function of metaphor and conducting a practical analysis of the metaphorical representation of the media image of Russian and Chinese armies. The research findings have shown that the "unity with the people" and the "ability to defend the country" form the basis of the image of the Chinese armed forces, while the image of the Armed Forces of the Russian Federation does not have a systematic metaphorical manifestation, the metaphors used for the Russian Army are isolated cases.
\end{abstract}

\section{Введение}

Вооруженные силы являются важным общественным институтом, призванным обеспечивать безопасность народа и государства от внешних угроз. При этом образ вооруженных сил, то есть представление граждан о своей армии, является одним из факторов успешной реализации вооруженными силами своего предназначения. В этой связи сопоставительные исследования имиджа армий приобретают особую актуальность на современном этапе развития гуманитарных наук.

Основным средством формирования образа общественных институтов являются средства массовой информации, поэтому объектом нашего исследования является медиаобраз, а основной исследовательской задачей является сопоставительный анализ метафорических репрезентаций медиаобраза Вооруженных сил Российской Федерации и Народно-освободительной армии Китая.

Подобное сопоставительное исследование представляется важным еще и потому, что и в России, и в Китае недавно были проведены военные реформы, нацеленные в том числе на создание позитивного имиджа армии. Так, «срезовый» дескриптивный анализ современного содержания образа армии в России и Китае может показать, насколько успешно была выполнена заложенная в реформе вооруженных сил идея по формированию позитивного институционального имиджа.

Кроме того, эмпирический анализ конкретных языковых моделей, используемых в медиадискурсе для метафорического переосмысления образа вооруженных сил, может расширить существующее понимание 
дискурсивной роли метафор и их функционального потенциала как средства формирования общественнополитических концептов.

Для достижения вышеуказанной цели исследования необходимо решить следующие задачи:

- осмыслить роль метафоры как средства создания медиаобраза с теоретической точки зрения;

- провести контент-анализ новостных сообщений в государственных СМИ РФ и КНР;

- выявить используемые метафорические модели, в которых в качестве сферы-цели используется «армия»;

- провести дескриптивный анализ выявленных метафорических моделей.

Для сопоставительного анализа метафорической репрезентации вооруженных сил в статье применяются теоретические методы исследования, такие как изучение и анализ отечественной и зарубежной литературы, методы теоретического синтеза и анализа, абстрагирования и конкретизации, а также эмпирические праксиметрические методы: контент-анализ, дискурс-анализ. Для обработки данных мы прибегали к методу расчета абсолютных и относительных величин.

Выявление метафор в новостных сообщениях базируется на валидной методике MIP VU (Deignan, 2015; PragglejazGroup, 2007), в основе которой лежит принцип сопоставления базового и контекстуального значений лексем.

Для практического исследования этого потенциала мы изучили по 100 текстов информационно-аналитического характера на китайском и русском языках, опубликованных в сети Интернет с мая 2015 года по июль 2021 года, касающихся вооруженных сил России и НОАК соответственно. Источниками материала на китайском языке явились такие издания, как «解放军报》 (газета «НОАК»), «新华》 (новостное агентство «Синьхуа»), 《人民日 报》 (газета «Женьминь Жибао»), «中华网军事》 (портал 《Чжунхуаван Цзюньши»), «中国共产党新闻网》 (новостное агентство «КПК»), на русском языке - новостные агентства TACC, RT, REGNUM, Коммерсантъ, Красная звезда.

Теоретической базой исследования являются представления о когнитивной природе метафоры (Лакофф, Джонсон, 2004), базовые положения дискурсивного подхода к метафоре (Musolff, 2016; Будаев, Чудинов, 2020; Калинин, 2020) и теоретические основания изучения институционального медиаобраза (Калинин, 2015; Русяева, Нешина, Черемушкина, 2018; Павлюченко, 2021).

Практическая значимость исследования заключается в том, что системное описание медиаобраза армии позволяет делать прогностические выводы об отношении населения страны к такому важному институту общества, как вооруженные силы. На наш взгляд, исследование носит междисциплинарный характер, а его результаты могут быть использованы в политологических, социологических работах, исследованиях в военной сфере и в области PR, а также в университетских курсах по стилистике, теории языка, лексикологии.

\section{Основная часть}

Метафора - это не только семантический перенос, основанный на концептуальном переосмыслении опыта взаимодействия с окружающим миром, в метафоре находят свое отражение категоризационные структуры, которые оказывают влияние на конструирование общественной реальности. Концептуальные метафорические переносы, будучи многократно реализованными в разных речевых репрезентациях в дискурсе, могут формировать определенный образ общественно-политического института, субъекта или явления. На наш взгляд, метафорические проекции в рамках дискурса способны оказывать значительное влияние на конструирование общественного мнения и на репрезентацию общественно-политических процессов в коллективном сознании граждан той или иной страны, что было многократно доказано на примере метафорической репрезентации коронавируса в СМИ разных стран (Кисель, 2020; Kalinin, 2021).

При этом функциональный потенциал метафор в дискурсе проявляется не только в формировании отношения к определенному явлению, субъекту или общественному институту. Метафоры также являются действенным инструментом создания имиджа, в частности институционального.

Процесс формирования институционального имиджа понимается нами как «целенаправленно создаваемый в речевой коммуникации абстрактный, частотный, эмоционально окрашенный образ субъекта политического процесса, обладающий высокой степенью информативности, возможностью развертывания в большой текст и обусловленностью политическим дискурсом, ретранслируемым медиапосредниками от непосредственного субъекта политического процесса к опосредованному субъекту восприятия речевого сообщения» (Калинин, 2018b, с. 47).

В частности, относительно политических метафор, которые чаще всего служат целям формирования образа государственных институтов, Н. Д. Арутюнова писала, что метафора - это неотъемлемый компонент политического текста, а «всеприсутствие» метафоры в речи, делает возможным ее использование в качестве средства для обозначения намерений автора в политическом дискурсе (Арутюнова, 1990, с. 18). По мнению А. П. Чудинова, «метафора - это важное средство воздействия на интеллект, чувства и волю адресата, она необычайно динамична, она понятна и действенна только “здесь и сейчас”, она вместе с тем согласована с основными понятиями данной культуры, имеет национальные корни» (Чудинов, 2001, с. 14).

В своих работах ранее мы также определили метафоричность «одним из важнейших признаков имиджевого политического медиатекста, как основы для формирования институционального имидж» (Калинин, 2018а, с. 55).

Так, метафора обладает семантической, когнитивной и эмоциональной силой воздействия, в полной мере отражает коммуникативные интенции автора коммуникативного сообщения, и потому этот прием широко употребляется в текстах разных дискурсов для формирования того или иного имиджа. 
В этой связи конструирование имиджа, в частности политического имиджа государства или его институтов, является одним из возможных реализаций функционального потенциала концептуальных метафор в дискурсе.

Анализ медиатекстов на китайском языке показывает, что использование приема метафорического переосмысления для репрезентации образа вооруженных сил является довольно частотным. Языковые формы этого метафорического переосмысления разнообразны - прямые метафоры, скрытые метафоры, метонимии.

Наиболее часто встречающимися метафорами образа НОАК стали:

1. Детище народа / сыны отечества

演员们真情实感的表演汇聚了各界群众对的真挚热爱, 表达了对建军91周年这一光辉节日的美好祝愿。/ Артисты сердечно передали искренние поздравления военнослужащим (сынам отчества) от лица представителей всех социальных слоев общества, выразили самые теплые поздравления с 91 годовщиной светлого праздника образования НОАК.

Эта метафорическая проекция базируется на концептуальной метафоре АРМИЯ - это РЕБЕНОК (народа). В данной метафоре важным является тот факт, что из сферы-источника РЕБЕНОК на сферу-цель переносится не признаки «инфантилизм», «необходимость в заботе», а концептуальное значение «неразрывной связи со страной». Эта метафора базируется на той же категории «родственные связи», что и уже стертая метафора РОДИНА - это МАТЬ/ОТЕЦ. Метафорическое осмысление института вооруженных сил через родственные связи призвано продемонстрировать тесную связь народа (родители) и армии (ребенка), их взаимозависимость. Данный метафорический перенос не только формирует образ самой армии, но и определяет направление концептуальной обработки отношения к вооруженным силам. СМИ, постулируя армию как «сынов Отечества», как бы обязывают народ относиться к своей армии как к своим детям.

Используя метафору «сыны отечества», китайские СМИ подчеркивают, что именно народ создал армию во время Наньчанского восстания под руководством Мао Цзэдуна 1 августа 1927 г. Отметим также, что родственные отношения являются крайне важными для китайской лингвокультуры, философский концепт, выражаемый в конфуцианском постулате 孝 («сыновья почтительность»), предполагает специфический формат отношений «родители-дети». Дети призваны почитать старших, беспрекословно подчиняться их воле, делать все для их блага, в то время как родители несут полную ответственность за своих детей, включая прежде всего их надлежащее морально-нравственное воспитание и материальное обеспечение.

Отметим, что нами была зафиксирована высокая частотность употребления данного выражения в различных китайских источниках, в 100 текстах эта метафора встретилась 15 раз.

2. Рыба и вода

解放军和武警部队按照打赢脱贫攻坚战总体部署, 在完成军事任务的同时, 积极参与脱贫攻坚行动, 奏响了军民鱼 水情的时代新乐章。/ Согласно генеральному плану по борьбе с бедностью, НОАК и НВМ, выполняя военные задачи, принимали активное участие в ликвидации бедности, тем самым сыграли «новую пьесу» в рамках концепции «народ и армия едины» (народ и армия как рыба и воде).

Метафорическое выражение 军民鱼水情 jūnmín yúshuǐqíng (Армия и народ неотделимы, как рыба и вода) встретилось в 8 текстах. Использование образа рыбы и воды в метафорическом переосмыслении взаимосвязи армии и народа еще раз концептуализирует их сильную взаимозависимость. Как известно, для рыб вода является жизненно необходимым ресурсом, так как они дышат кислородом, который растворен в воде, и не могут дышать воздухом. В данном случае рыба - это армия, а народ представляется в образе жизненно важного компонента, которая обеспечивает жизнедеятельность армии.

3. Позвоночник страны

既然说要改革体制编制, 那就要下功夫动真格, 就像李克强说的那样, 壮士断腕的决心, 军队是国家民族的奉梁。/ Если говорить о необходимости реформирования системы комплектования вооруженных сил, то нужно приложить усилия и взяться за этот вопрос по-настоящему. Премьер Ли Кецян говорил, что мы можем пойти на крайние шаги, ведь армия - это скелет (позвоночник) нации.

Метафорическая проекция АРМИЯ - это ПОЗВОНОЧНИК встретилась в исследуемых текстах 5 раз. Данная метафора переносит концептуальные признаки позвоночника как «основы, поддерживающей положение всего организма», на роль вооруженных сил. Таким образом, создается образ, что армия для Китая является главной составляющей всей структуры (скелета) государства, является тем общественным институтом, который позволяет всей стране «оставаться в вертикальном положении» и «осуществлять движение».

4. Железная китайская стена

强大的国防力量, 强大的人民, 铸就了和平时期的铁长城, 这是一座能够绝对保卫祖国和人民安全的钢铁长城。/ Мощные вооруженные силы, сильный народ отлили железную стену новой эпохи. Это железная стена народной безопасности, способная в полной мере защитить наше Отечество.

Эта метафора встретилась чаще всего - 21 раз, то есть более чем в 20\% исследованных новостных сообщениях мы столкнулись именно с таким метафорическим образом НОАК.

В этой метафоре НОАК предстает в образе «Великой Китайской стены» (长城), которая, как известно, на протяжении многих столетий являлась для китайцев своеобразным щитом от внешних врагов. Таким образом «стена» стала символом защиты от врагов, а определение «стальная» говорит об ее высочайшей устойчивости и нерушимости. В сознании китайцев это выражение интерпретируется как «Нерушимая и несокрушимая оборонная сила, в лице НОАК, которая обеспечивает сохранность территориальной целостности». 
Регулярное появление в СМИ метафоры 钢铁长城 gāngtiě chángchéng («стальная стена» позволяет определить данную метафору как языковой штамп, устоявшийся в массовом сознании китайцев.

5. Поборник суверенитета

按照新的历史使命的要求, 我军不仅要维护国家的《领土边疆》, 还要维护国家的《利益边疆》; 不仅要成为国家安全 利益的捍卫者, 还要成为国家发展利益的捍卫者。/ Согласно требованиям исторической миссии наша армия должна не только защищать территориальную целостность границ государства, но также защищать границы наших интересов. Армия должна быть не только поборником интересов безопасности государства, но и поборником интересов развития государства.

В данном случае мы сталкиваемся с олицетворением вооруженных сил, наделением общественного института характеристиками, присущими человеку. Значение слова 捍卫者 hànwèi zhě - это «лицо, которое охраняет, оберегает...», оно образовано суффиксальным способом посредством присоединения к лексеме 捍卫 (охранять, оберегать) суффикса 者со значением «деятель; тот, кто совершает действие». В данном контексте НОАК представляется в образе человека-защитника, который стоит на страже суверенитета всего государства.

6. Милые люди

他们 (解放军) 是新时代最可爱的人 tāmen (jiěfàngjūn) shì xīn shídài zuì kě'ài de rén。 / Они (НОАК) являются самыми «милыми людьми» новой эпохи.

Это метафорический неологизм довольно часто встречается в китайских СМИ - 13 раз. Данное выражение, впервые было употреблено журналистом Вэйвей (魏巍) 4 ноября 1951 года в китайской газете «Женьмин жибао», в статье, которая называлась «谁是最可爱的人» (Кто же самые «милые люди»), где он ласково назвал армию своей страны «милыми людьми». Это выражение сразу же укоренилось в народе, и сейчас является устойчивым выражением, метонимией НОАК. Слово 可爱 kě́ài переводится на русский язык, как «очаровательный, милый, прелестный, славный». В сознании людей создается образ культурной, вежливой и неагрессивной армии, которая ни в коем случае не станет агрессором и провокатором войны или военных действий.

Рассмотрим количественное распределение метафор, используемых для формирования образа НОАК.

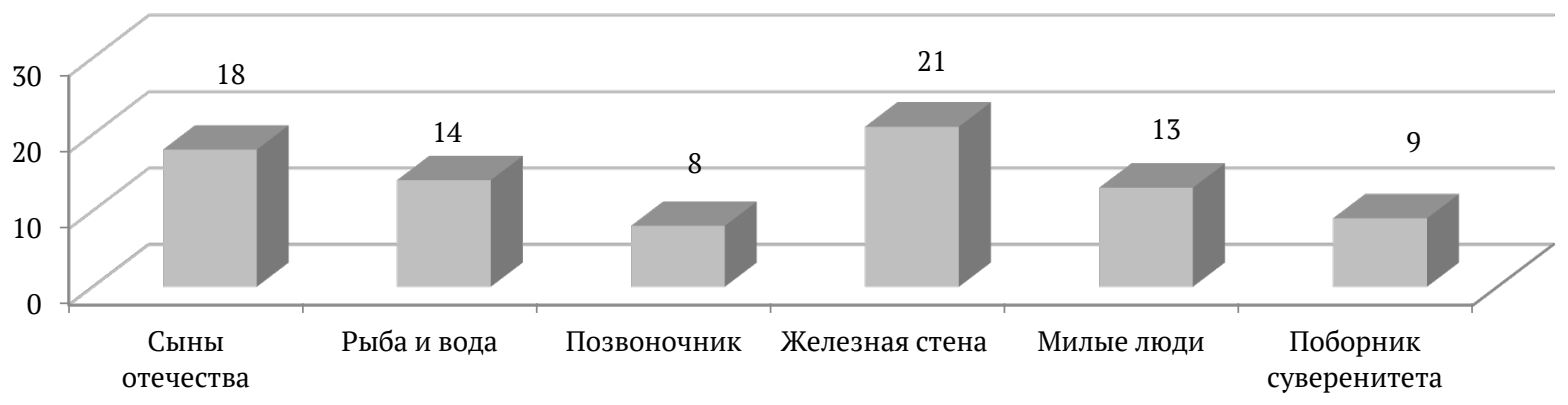

Рисунок 1. Количественные показатели употребления метафор при формировании образа армии Китая

Как мы видим на Рис. 1, наиболее употребительными являются метафоры «сыны отечества», «железная стена» и «рыба и вода», которые связаны с единением армии и народа, с их неразрывной связью. Кроме того, метафора китайской стены тесно связана с культурным кодом китайской нации и подчеркивает жизненно важную роль НОАК по обеспечению безопасности территории страны.

В России на современном этапе развития вооруженных сил уделяется большое внимание формированию положительного образа вооруженных сил. После перестройки политической и экономической системы и проведения масштабной военной реформы высшее военно-политическое руководство России приступило к планомерной работе по улучшению имиджа военной службы и вооруженных сил в целом.

Отметим, что, согласно последним данным социологического опроса ВЦИОМ, каждый второй из опрошенных респондентов (52\%) ответил положительно на вопрос: хотели бы вы, чтобы ваш сын, брат муж или другой близкий родственник служил сейчас в армии. $40 \%$ ответили отрицательно, а $8 \%$ затруднились дать ответ. В способность армии защитить страну в случае реальной угрозы верят 83\% опрошенных, $12 \%$ - не верят. Также россиян спросили, доверяют ли они министру обороны РФ Сергею Шойгу. $78 \%$ выказали доверие, 16\% - нет. В 2018 году 79\% доверяли, 10\% не доверяли. ВЦИОМ также сообщил, что деятельность армии одобряют 78,9\% (Блинов, 2021).

При этом мы не можем не отметить, что в отечественном языкознании не проводилось исследований метафорического образа Вооруженных сил Российской Федерации, исследований каких-либо других способов репрезентации имиджа армии России также не проводилось.

Отдельные работы касались изучения лингвистических средств репрезентации вооруженных сил нашей страны в исторической парадигме. Например, О. В. Рычкова изучила образ Красной Армии в американской прессе середины 20 века (Рычкова, 2008), а В. С. Еремин - образ русской армии времен наполеоновский войн (Еремин, 2020). Вопросу формирования образа современной армии не посвящено ни одного исследования.

Отметим, что в отобранных нами для анализа новостных текстах на русском языке мы также не выявили ярких и систематических метафорических образов Вооруженных сил Российской Федерации. 
Исключение составляет метонимия «вежливые люди», появившаяся после событий в Крыму в 2014 году. Меткое выражение одного из жителей Крыма в телевизионном интервью мгновенно стало мемом и приклеилось к образу Вооруженных сил России на современном этапе. Образ красивого, молодого человека в форме, который передает котенка ребенку, стал, вероятно, главным символом армии России на современном этапе, так как он был повторен многократно всеми СМИ, одежда с этим образом стала модной, а в Симферополе появился памятник «вежливым людям». Военно-политическое руководство нашей страны также активно пользовалось данной метонимией. Так, согласно статье в РИА НОВОСТИ, Министр обороны РФ С. К. Шойгу пошутил насчет «вежливых людей», комментируя утверждения Киева о причастности российского спецназа к происходящему в Донбассе: «Скажу лишь одно - трудно искать черную кошку в темной комнате, особенно если ее там нет. Тем более глупо, если эта кошка умная, смелая и вежливая» (Зарембо, 2014).

Еще одним имеющимся в нашем языковом сознании образом вооруженных сил является образ «сынов отечества». Это устойчивое словосочетание появилось еще в советское время, и оно часто используется для наименования разного рода военно-патриотических конкурсов. Также оно применятся и для описания молодых военнослужащих.

На наш взгляд, резкий рост популярности образа «вежливые люди» демонстрирует запрос российского общества на определенный устоявшийся образ для российских вооруженных сил. Отсутствие яркого, понятного народу и отражающего суть развития вооруженных сил на современном этапе метафорического образа на фоне роста имиджа армии в обществе кажется странным и нелогичным. Кроме того, подобный образ должен иметь четкую вербальную формулу, которая должна многократно транслироваться СМИ, тогда отношение народа к армии будет более устойчивым, а имидж военной службы продолжит улучшаться.

Таким образом, анализ средств массовой информации КНР и РФ показал разную картину по формированию институционального образа вооруженных сил страны. В КНР образ Народно-освободительной армии главным образом базируется на сферах-источниках, концептуализирующих тесную связь армии и народа, тем самым как бы наделяя и народ, и армию определенными общественными обязательствами по отношению друг к другу. В российских СМИ, к сожалению, не ведется целенаправленной работы по формированию образа посредством внедрения в массовое сознание концептуальных метафорических моделей, что, на наш взгляд, во многом препятствует формированию позитивного имиджа нашей армии.

\section{Заключение}

Проведенное нами на материале дискурса массмедиа практическое исследование демонстрируют высокий функциональный потенциал метафорических выражений по конструированию общественного мнения и созданию образа государственных институтов.

Анализ метафорического выражения образа вооруженных сил продемонстрировал отсутствие этого образа у Вооружённых сил России на современном этапе и поступательное формирование концептуального содержания образа армии в Китае.

Таким образом, мы можем утверждать, что содержательный анализ речевых моделей концептуальных метафор является действенным средством исследования имиджеобразующей функции метафор в дискурсе. Он позволяет не только констатировать факт формирования новых концептов, связанных с тем или иным образом, но и выявить содержательную составляющую этих концептов.

Перспективы дальнейшего исследования проблемы с точки зрения теории мы видим в более детальном изучении имиджеообразующей функции метафоры в дискурсе. С практической точки зрения мы полагаем значимым продолжить поступательное изучение процесса формирования образа России и ее государственных институтов в рамках междисциплинарных исследований.

\section{Источники | References}

1. Арутюнова Н. Д. Метафора и дискурс // Теория метафоры: сборник. М.: Прогресс, 1990.

2. Блинов М. ВЦИОМ: россияне верят в способность армии защитить их от военной угрозы. 2021. URL: https://ria.ru/20210615/armiya-1737011642.html

3. Будаев Э. В., Чудинов А. П. Современная российская политическая метафорология (2011-2020 гг.) // Филологический класс. 2020. Т. 25. № 2.

4. Еремин В. С. Русская армия глазами британских публицистов “THE QUARTERLY REVIEW” в годы наполеоновских войн // История и историческая память. 2020. Т. 21.

5. Зарембо И. «Вежливые люди» как новый образ Российской армии. 2014. URL: https://ria.ru/20140516/ 1007988002.html

6. Калинин О. И. Дискурсивная метафора и метафора в дискурсе: к вопросу о дискурсообразующей роли когнитивной метафоры // Когнитивные исследования языка. 2020. Т. 3. № 42.

7. Калинин О. И. Метафорический образ НОАК в СМИ КНР // Политическая лингвистика. 2018а. Т. 6. № 72.

8. Калинин О. И. Основы лингвопрагматического исследования политического имиджа. М.: КноРус, $2018 \mathrm{~b}$.

9. Калинин О. И. Политический имидж России в СМИ КНР: к вопросу о тональности текста в связи с событиями на Украине // Политическая лингвистика. 2015. Т. 1. № 51. 
10. Кисель И. Ф. Метафорическая репрезентация понятия «коронавирус»в медиадискурсе (на материале русского и немецкого языков) // Вестник Адыгейского государственного университета. Серия 2. Филология и искусствоведение. 2020. Т. 4. № 627.

11. Лакофф Д., Джонсон М. Метафоры, которым мы живём. М.: Едиториал УРСС, 2004.

12. Павлюченко А. А. Образ России в американских СМИ (на примере публикаций сайтов телеканалов СNN и FOX NEWS) // Социальные и гуманитарные науки. Отечественная и зарубежная литература. Серия 11. Социология Реферативный журнал. 2021. Т. 3.

13. Русяева М. М., Нешина Е. Б., Черемушкина Е. Ф. Россия глазами Европы. Имидж страны через призму языка / Всероссийский государственный университет юстиции (РПА Минюста России) в г. Саранске. Саранск: ЮрЭксПрактик, 2018.

14. Рычкова О. В. Образ Красной Армии в американской прессе в конце Второй мировой войны // Военноисторический журнал. 2008. Т. 10.

15. Чудинов А. П. Россия в метафорическом зеркале: когнитивное исследование политической метафоры (1991-2000): монография. Екатеринбург: УрГПУ, 2001.

16. Deignan A. MIP, the corpus and dictionaries: What makes for the best metaphor analysis? // Metaphor and Social World. 2015. T. 5. № 1.

17. Kalinin O. Comparative Analysis of Coronavirus Metaphoric Representation in Chinese and Russian Online Media // Acta Linguistica Asiatica. 2021. T. 11. № 2.

18. Musolff A. Political Metaphor Analysis: Discourse and Scenarios. L.: Bloomsbury Publishing, 2016.

19. PragglejazGroup. MIP: A method for identifying metaphorically used words in discourse // Metaphor and Symbol. 2007. T. 22. № 1 .

\section{Информация об авторах | Author information}

RU Калинин Олег Игоревич ${ }^{1}$, к. филол. н. Радус Лариса Александровна ${ }^{2}$

${ }^{1}$ Военный университет Министерства обороны Российской Федерации, г. Москва; Московский государственный лингвистический университет

${ }^{2}$ Военный университет Министерства обороны Российской Федерации, г. Москва

EN Kalinin Oleg Igorevich ${ }^{1}, \mathrm{PhD}$

Radus Larisa Aleksandrovna ${ }^{2}$

${ }^{1}$ Military University of the Ministry of Defense, Moscow;

Moscow State Linguistic University

${ }^{2}$ Military University of the Ministry of Defense, Moscow

${ }^{1}$ okalinin.lingua@gmail.com, ${ }^{2}$ lara_rad@bk.ru

\section{Информация о статье | About this article}

Дата поступления рукописи (received): 07.11.2021; опубликовано (published): 28.12.2021.

Ключевые слова (keywords): медиаобраз вооруженных сил; метафорический образ; метафорическая репрезентация; media image of the armed forces; metaphorical image; metaphorical representation. 